\title{
Synthesis and Biological Evaluation of Novel $\boldsymbol{\gamma}$-Alkylidene Butenolides
}

\author{
Gai-Zhi Liu, ${ }^{1}$ Yan-Bin Guan, ${ }^{1}$ Ya Wu, ${ }^{1}$ and Hong-Min Liu ${ }^{2}$ \\ ${ }^{1}$ School of Pharmacy, Henan University of Traditional Chinese Medicine, Zhengzhou, Henan 450046, China \\ ${ }^{2}$ School of Pharmaceutical Science, Zhengzhou University, Ke Xue Da Dao 100, Zhengzhou 450001, China \\ Correspondence should be addressed to Gai-Zhi Liu; liugaizhi@126.com
}

Received 7 May 2013; Revised 10 July 2013; Accepted 14 July 2013

Academic Editor: Augusto C. Tome

Copyright ( 2013 Gai-Zhi Liu et al. This is an open access article distributed under the Creative Commons Attribution License, which permits unrestricted use, distribution, and reproduction in any medium, provided the original work is properly cited.

Three new series of 4-substituted-5-alkylidene-2,5-dihydrofuran-2-ones were synthesized. The in vitro activity test results showed that some of them exhibited good antibacterial and cytotoxic activities. Among them compound 5c showed the most potent antibacterial activity against Escherichia coli with the MIC value of $20.00 \mu \mathrm{g} / \mathrm{mL}$. Compound 9c showed good cytotoxic activity against Ec9706 cells with $\mathrm{IC}_{50}$ value of $19.39 \mu \mathrm{M}$, better than that of the reference compound fluorouracil $\left(\mathrm{IC}_{50}=37.74 \mu \mathrm{M}\right)$.

\section{Introduction}

The biological importance of unsaturated lactones is well known [1-8]. In particular, $\gamma$-alkylidene butenolide is an important class of organic compounds that is present in many synthetic bioactive molecules and natural products, such as rubrolides (a) $[9,10]$, nostoclides (b) [11-13], and uncinine (1) $[14,15]$ (Figure 1). Most of them exhibit various interesting biological activities, such as antibacterial, anticancer, antibiotic, and phospholipase A2 inhibition activity [16-26]. Over the past few decades, many researchers have been engaged in the synthesis of $\gamma$-alkylidene butenolides and their analogues due to their promising biological activities.

In the previous literatures [27, 28], pulvinones (2) were synthesized and evaluated as inhibitors of early stage cell wall biosynthesis enzymes MurA-MurD. Several pulvinones inhibited Mur enzymes with $\mathrm{IC}_{50} \mathrm{~s}$ in the $1-10 \mu \mathrm{M}$ range and demonstrated antibacterial activity against Grampositive bacteria including methicillin-resistant Staphyloccucos aureus, vancomycin-resistant Enterococcus faecalis, and penicillin-resistant Streptococcus pneumoniae. A series of $\alpha, \beta$-unsaturated- $\gamma$-lactone-free nitrogen-containing heterocyclic analogues of solamin, a natural mono-THF acetogenin, have been synthesized, and their cytotoxicity was investigated against 39 tumor cell lines. One of them, 1-methyl -pyrazol-5yl derivative, showed selective increase of cytotoxicity against
NCI-H23 with 80 times higher potency than solamin [2937]. The synthesis and bioactivity of the $\alpha, \beta$-unsaturated- $\gamma$ alkylidene butenolides containing nitrogen atom or nitrogen heterocyclic unit were reported few times $[14,15]$.

\section{Results and Discussion}

Based on the previous researches and our previous work on the synthesis and bioactivity of $\gamma$-alkylidene buteno-lides [38-41], series of new $\alpha, \beta$-unsaturated- $\gamma$-lactones bearing a nitrogen-containing unit such as piperazine and piperidine are designed and synthesized in the present work. The antibacterial and cytotoxic activities of the synthetic compounds were also evaluated.

The synthesis of compound $\mathbf{3}$ was reported in early studies [42-44]. The butenolide intermediates $\mathbf{4}, \mathbf{6}$, and 8 were prepared via introducing nitrogen-containing moiety such as piperazine or piperidine to the $\mathrm{C}-4$ position of the lactone 3 in good yields (Scheme 1). In this reaction, secondary amines were logical choice as nucleophiles because of the base-sensitive nature of the butenolide 3 . In addition, lower alkalinity catalysts such as $\mathrm{Na}_{2} \mathrm{CO}_{3}$ were used in the nucleophilic substitution reaction. The corresponding amines piperidine, methyl benzylamine, and benzoyl piperazine are all secondary amines, so the catalyst must be relatively weak alkaline in order to avoid the occurrence of adverse 


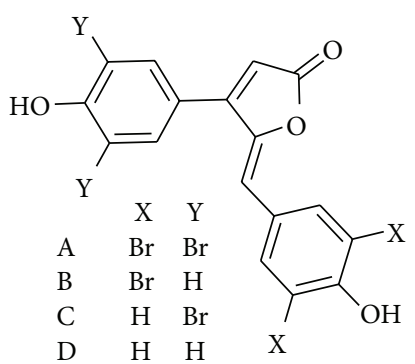

Rubrolides (a)<smiles>[X]c1cc(/C=C2\OC(=O)C(Cc3ccccc3)=C2C(C)C)cc(Cl)c1O</smiles>

Nostoclides (b)<smiles>CC(C)=C1C=C(CN2CCCC2=O)C(=O)O1</smiles>

Uncinine (1)<smiles>[R]C=C1OC(=O)C([R])=C1O</smiles>

Pulvinones (2)

FIGURE 1: Representative examples of $\gamma$-alkylidene butenolides.

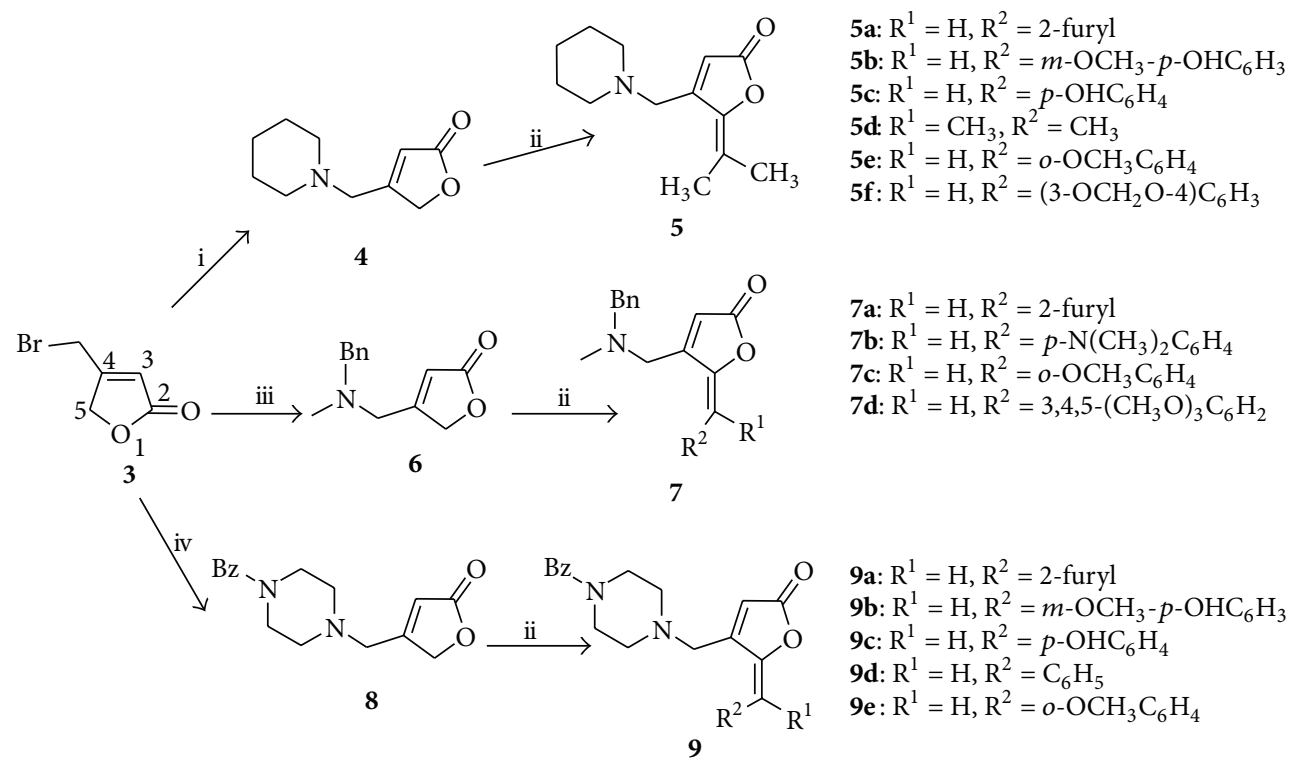

Scheme 1: Reagents and conditions: (i) 1.2 eq. piperidine, $\mathrm{CH}_{3} \mathrm{CN}, \mathrm{Na}_{2} \mathrm{CO}_{3}$, r.t. 3 h, $85 \%$; (ii) 1.2 eq. aldehyde, $\mathrm{Na}_{2} \mathrm{CO}_{3}, \mathrm{CH}_{3} \mathrm{OH}$, r.t. $3-12$ h; (iii) 1.2 eq. methyl benzylamine, $\mathrm{CH}_{3} \mathrm{CN}, \mathrm{Na}_{2} \mathrm{CO}_{3}, 60^{\circ} \mathrm{C}, 3 \mathrm{~h}, 90 \%$; (iv) 1.1 eq. benzoyl piperazine, $\mathrm{CH}_{3} \mathrm{CN}_{2} \mathrm{Na}_{2} \mathrm{CO}_{3}$, r.t. $2 \mathrm{~h}, 95 \%$.

reaction. Compounds $\mathbf{4}, \mathbf{6}$, and $\mathbf{8}$ were reacted with various aromatic aldehydes to produce a series of novel $\gamma$-alkylidene butenolides 5, 7, and $\mathbf{9}$ except for compound $\mathbf{5 d}$ (compound 4 was reacted with acetone to produce $\mathbf{5 d}$ ). The structures of compounds 5,7 , and $\mathbf{9}$, including the stereochemistry of the exocyclic carbon-carbon double bond, were established by $1 \mathrm{D}$ and $2 \mathrm{D}$ NMR spectroscopy. In the NMR spectrum of $5 \mathrm{c}$ and $9 \mathrm{c}$ (Figure 2), single peaks at $\delta \mathrm{H} 6.41$ and $\delta \mathrm{H}$ 6.40 , respectively, could be observed, suggesting the products were single isomers. In order to determine the geometry at the double bonds $\left(\Delta^{5,11}\right)$ of $5 \mathrm{c}$ and $9 \mathrm{c}$ (Figure 2 ), NOESY experiment was investigated. The correlation between $\mathrm{H}-11$ at $\delta \mathrm{H} 6.41$ of $5 \mathrm{c}$ and $\mathrm{H}-6$ proved that the geometry of the double bond $\left(\Delta^{5,11}\right)$ in the structure of $\mathbf{5 c}$ is $\mathrm{Z}$ configuration. The stereochemistry of $\mathbf{9 c}$ was similar to that of 5c. Similarly, most of the other synthetic compounds were confirmed to be single isomers, in which the geometry of the double bond $\left(\Delta^{5,11}\right)$ is $\mathrm{Z}$ configuration.

The antibacterial activity ${ }^{1}$ in vitro of compounds 5,7 , and 9 was evaluated against Escherichia coli and Staphylococcus aureus as described in Table 1. Among them is compound 5c with potent antibacterial activity against Escherichia coli $(\mathrm{MIC}=20 \mu \mathrm{g} / \mathrm{mL})$, which was better than antibacterial drug chloramphenicol $\left(\mathrm{MIC}_{90}=110 \mu \mathrm{g} / \mathrm{mL}\right)$. The results indicated that the introduction of the nitrogen heterocyclic and $\gamma$ alkylidene to the lactone was favorable for the antibacterial activity in some cases.

The cytotoxic activity ${ }^{2}$ in vitro of synthetic $\gamma$-alkylidene butenolides was also investigated against Ec9706 cells, Hela cells, SPCA1 cells, and HepG-2 cells. In cytotoxic activity test, first, each compound was tested at $100 \mu \mathrm{M}$ concentration if the compounds show no inhibitory activity for each selected cell, their $\mathrm{IC}_{50}$ values would not be tested. The results were described in Table 2. Some of them showed good cytotoxic activity. Among them compound 9c showed excellent cytotoxic activity against Ec9706 cells with $\mathrm{IC}_{50}$ value of $19.39 \mu \mathrm{M}$, which was better than that of the standard drug Fluorouracil $\left(\mathrm{IC}_{50}=37.74 \mu \mathrm{M}\right)$. Meanwhile, it exhibited good cytotoxic activity against HepG-2 and SPCA1 with $\mathrm{IC}_{50}$ values of $49.96 \mu \mathrm{M}$ and $50.15 \mu \mathrm{M}$, respectively. The results 


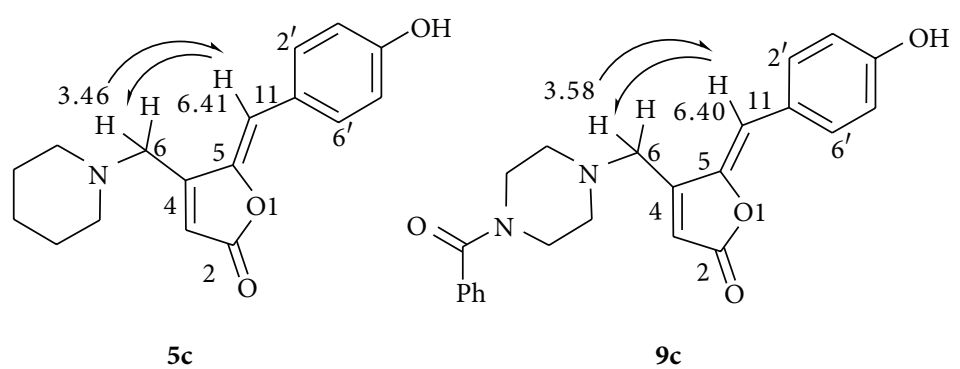

Figure 2: The NOE spectra of compounds $\mathbf{5 c}$ and $\mathbf{9 c}$.

TABLE 1: MIC ${ }^{\mathrm{a}, \mathrm{b}}$ of butenolide derivatives against Escherichia coli and Staphylococcus aureus.

\begin{tabular}{lccccc}
\hline Com & $\mathrm{EC}^{\mathrm{c}}$ & $\mathrm{SA}^{\mathrm{d}}$ & Com & $\mathrm{EC}^{\mathrm{c}}$ & $\mathrm{SA}^{\mathrm{d}}$ \\
\hline $\mathbf{3}$ & 120.13 & 101.46 & $\mathbf{7 b}$ & 82.58 & 82.58 \\
$\mathbf{4}$ & 90.83 & 90.83 & $\mathbf{7 c}$ & $\mathrm{Nd}^{\mathrm{e}}$ & $\mathrm{Nd}$ \\
$\mathbf{5 a}$ & 79.30 & 93.59 & $\mathbf{7 d}$ & $\mathrm{Nd}$ & $\mathrm{Nd}$ \\
$\mathbf{5 b}$ & $>200$ & $>200$ & $\mathbf{8}$ & 93.59 & 93.59 \\
$\mathbf{5 c}$ & 20.00 & 99.10 & $\mathbf{9 a}$ & 132.58 & 132.58 \\
$\mathbf{5 d}$ & 82.58 & 100.56 & $\mathbf{9 b}$ & 93.59 & 93.59 \\
$\mathbf{5 e}$ & 82.58 & 82.58 & $\mathbf{9 c}$ & 90.83 & 110.62 \\
$\mathbf{5 f}$ & 93.59 & 93.59 & $\mathbf{9 d}$ & 90.83 & 90.83 \\
$\mathbf{6}$ & $\mathrm{Nd}^{\mathrm{e}}$ & $\mathrm{Nd}$ & $\mathbf{9 e}$ & 82.58 & 82.58 \\
$\mathbf{7 a}$ & 82.58 & $>200$ & Chloramphenicol & 64 & $110^{\mathrm{f}}$ \\
\hline
\end{tabular}

${ }^{\mathrm{a}} \mathrm{MIC}(\mu \mathrm{g} / \mathrm{mL})$ : minimum inhibitory concentration.

${ }^{b}$ Defined as $100 \%$ inhibition of the growth of control. ${ }^{\mathrm{c}}$ Escherichia coli;

${ }^{\mathrm{d}}$ Staphylococcus aureus. ${ }^{\mathrm{e}}$ No detection. ${ }^{\mathrm{f}} \mathrm{MIC} 90(\mu \mathrm{g} / \mathrm{mL})$.

indicated that the introduction of the nitrogen heterocyclic and $\gamma$-alkylidene to the lactone was efficient for the cytotoxic activity in some case.

\section{Experimental}

3.1. Chemistry. All reagents and solvents were obtained from commercial suppliers. All the reactions were monitored by TLC. Melting points were determined on a Beijing Keyi XT5 apparatus, and the temperature was not corrected. IR spectra were recorded as $\mathrm{KBr}$ pellets on a Thermo Nicolet (IR200) Spectrometer. ${ }^{1} \mathrm{H}$ and ${ }^{13} \mathrm{C}$ NMR spectra were recorded on a Bruker DPX-400 spectrometer at 400 and $100 \mathrm{MHz}$ with TMS as internal standard. Mass spectra were taken by Waters Q-Tof micromass spectrometer.

3.1.1. 4-(Piperidin-1-ylmethyl)furan-2(5H)-one (4). To an $\mathrm{CH}_{3} \mathrm{CN}(50 \mathrm{~mL})$ solvent of compound $3(0.1 \mathrm{~mol})$ and anhydrous sodium carbonate $(0.06 \mathrm{~mol}) 1.2$ eq. piperidine $(0.12 \mathrm{~mol})$ was added. The mixture was stirred at room temperature for $3 \mathrm{~h}$, and the reaction was monitored by TLC until completion, the solid salt was filtered, and the filtrate was evaporated under reduced pressure to steam out of most of the acetonitrile, the reaction mixture was washed with water and ethyl acetate, dried and purified by column chromatography (elution with chloroform ether-ethylacetate,
$3: 1)$ which afforded $15.4 \mathrm{~g}$ compound 4 . Yield: $85 \%$, yellow oil. IR ( $\mathrm{KBr}, \mathrm{cm}^{-1}$ ): 1762, 1630, 1489, 1462, 1438, 1284, 1247, 1024, 994, and 758. ${ }^{1} \mathrm{H} \mathrm{NMR}\left(400 \mathrm{MHz}, \mathrm{CDCl}_{3}, \mathrm{ppm}\right) \delta$ : $5.98(\mathrm{~s}, 1 \mathrm{H},=\mathrm{CH}), 4.82(\mathrm{~s}, 2 \mathrm{H}), 3.31(\mathrm{~s}, 2 \mathrm{H}), 2.38(\mathrm{~s}, 4 \mathrm{H})$, and 1.61-1.26 (m, overlap, $6 \mathrm{H}) ;{ }^{13} \mathrm{C} \mathrm{NMR} \mathrm{(100.6} \mathrm{MHz,} \mathrm{CDCl}_{3}$, ppm) $\delta$ : 173.8 (C2), 168.4, 117.1, 72.7, 56.7, 55.0, 25.8, and 23.9. HR-MS (ESI), calcd. $\mathrm{C}_{10} \mathrm{H}_{15} \mathrm{NO}_{2}:[\mathrm{M}+\mathrm{H}]^{+} \mathrm{m} / z$ : 182.1181; found: 182.1160 (see Supplementary Material available online at http://dx.doi.org/10.1155/2013/926723).

3.1.2. General Procedure for the Preparation of (5a-f). Compound $4(0.01 \mathrm{~mol})$ and anhydrous sodium carbonate $(0.01 \mathrm{~mol})$ were dissolved in $\mathrm{MeOH}(50 \mathrm{~mL})$ solvent, then the respective aromatic aldehyde (acetone for compound $\mathbf{5 d}$ ) $(0.012 \mathrm{~mol})$ was added. The mixture was stirred at room temperature for $3-12 \mathrm{~h}$, and the reaction was monitored by TLC until completion. The reaction solution was evaporated under reduced pressure to steam out of most of the methanol solvent. the reaction mixture was washed with water and ethyl acetate, dried, and purified by column chromatography.

(Z)-5-(Furan-2-ylmethylene)-4-(piperidin-1-ylmethyl)furan-2 (5H)-one (5a). Yield: $60 \%$, brown oil. IR $\left(\mathrm{KBr}, \mathrm{cm}^{-1}\right): 2923$, 2848, 1627, 1446, and 1382. ${ }^{1} \mathrm{H}$ NMR (400 MHz, $\mathrm{CDCl}_{3}$, ppm) $\delta: 7.50(\mathrm{~d}, J=1.38 \mathrm{~Hz}, 1 \mathrm{H}, \mathrm{Ar}), 7.05(\mathrm{~d}, J=3.39 \mathrm{~Hz}, 1 \mathrm{H}$, $\mathrm{Ar}), 6.54(\mathrm{~m}, 1 \mathrm{H}, \mathrm{Ar}), 6.53(\mathrm{~s}, 1 \mathrm{H},=\mathrm{CH}), 6.09$ (s, 1H, =CH), $3.42(\mathrm{~s}, 2 \mathrm{H}), 2.43(\mathrm{~s}, 4 \mathrm{H}), 1.63(\mathrm{~m}, 4 \mathrm{H})$, and $1.47(\mathrm{~m}, 2 \mathrm{H}) ;{ }^{13} \mathrm{C}$ NMR (100.6 MHz, $\left.\mathrm{CDCl}_{3}, \mathrm{ppm}\right) \delta$ : 168.9 (C2), 156.4, 149.0, 146.1, 143.9, 116.0, 115.3, 113.0(C11), 100.2, 54.9, 25.9, and 24.0. HR-MS (ESI), calcd. $\mathrm{C}_{15} \mathrm{H}_{17} \mathrm{NO}_{3}:[\mathrm{M}+\mathrm{H}]^{+} \mathrm{m} / z$ : 260.1287; found: 260.1243 .

(Z)-5-(4-Hydroxy-3-methoxybenzylidene)-4-(piperidin-1ylmethyl)furan-2(5H)-one (5b). Yield: $65 \%$, yellow oil. IR $\left(\mathrm{KBr}, \mathrm{cm}^{-1}\right): 2924,1623,1516,1382$, and $1124 .{ }^{1} \mathrm{H}$ NMR $\left(400 \mathrm{MHz}, \mathrm{CDCl}_{3}, \mathrm{ppm}\right) \delta: 7.53(\mathrm{~d}, J=1.76 \mathrm{~Hz}, 1 \mathrm{H}, \mathrm{Ph})$, $7.18(\mathrm{dd}, J=1.80 \mathrm{~Hz}, 8.24 \mathrm{~Hz}, 1 \mathrm{H}, \mathrm{Ph}), 6.93$ (d, $J=8.24 \mathrm{~Hz}$, $1 \mathrm{H}, \mathrm{Ph}), 6.34(\mathrm{~s}, 1 \mathrm{H},=\mathrm{CH}), 6.08(\mathrm{~s}, 1 \mathrm{H},=\mathrm{CH}), 3.96(\mathrm{~s}, 3 \mathrm{H}$, $\left.\mathrm{OCH}_{3}\right), 3.46(\mathrm{~s}, 2 \mathrm{H}), 2.46(\mathrm{~s}, 4 \mathrm{H}), 1.63(\mathrm{~m}, 4 \mathrm{H})$, and $1.46(\mathrm{~m}$, $2 \mathrm{H}) ;{ }^{13} \mathrm{C} \mathrm{NMR}\left(100.6 \mathrm{MHz}, \mathrm{CDCl}_{3}, \mathrm{ppm}\right) \delta: 169.6$ (C2), 157.2, $147.1,146.8,146.5,127.5,125.7,115.0,114.6,111.5,111.7$ (C11), 56.1, 54.9, $54.8\left(\mathrm{OCH}_{3}\right), 25.9$, and 24.0. HR-MS (ESI), calcd. $\mathrm{C}_{18} \mathrm{H}_{21} \mathrm{NO}_{4}:[\mathrm{M}+\mathrm{H}]^{+} \mathrm{m} / z$ : 316.1549; found: 316.1537.

(Z)-5-(4-Hydroxybenzylidene)-4-(piperidin-1-ylmethyl)furan$2(5 \mathrm{H})$-one (5c). Yield: $85 \%$, sallow crystal mp: $178.3-179.5^{\circ} \mathrm{C}$. 
TABLE 2: ${ }^{a} \mathrm{IC}_{50}$ values of butenolides against Ec9706 cells, Hela cells, SPCA1 cells and HepG-2 cells.

\begin{tabular}{lccccccccc}
\hline Com & Ec9706 & HepG-2 & SPCA1 & Hela & Com & Ec9706 & HepG-2 & SPCA1 & Hela \\
\hline $\mathbf{3}$ & 89.45 & 97.38 & 100.02 & 92.87 & $\mathbf{7 b}$ & 81.34 & NI & NI & 113 \\
$\mathbf{4}$ & 78.23 & 80.16 & 108 & 70.36 & $\mathbf{7 c}$ & NI $^{\text {b }}$ & 116 & NI & 84.28 \\
$\mathbf{5 a}$ & 50.69 & 56.87 & NI & NI & $\mathbf{7 d}$ & 104 & 178 & 89.19 & Nd $^{\text {c }}$ \\
$\mathbf{5 b}$ & 100 & 88.64 & 200 & 90.16 & $\mathbf{8}$ & NI $^{\text {b }}$ & 102 & 116 & 128 \\
$\mathbf{5 c}$ & 76.34 & 66.58 & 80.25 & 56.37 & $\mathbf{9 a}$ & 77.59 & 67.51 & 102 & 86.31 \\
$\mathbf{5 d}$ & $\mathrm{NI}$ & $\mathrm{NI}$ & $\mathrm{NI}$ & $\mathrm{Nd}$ & $\mathbf{9 b}$ & 131 & 59.13 & 106 & 156 \\
$\mathbf{5 e}$ & 96.12 & 132 & 101 & 87.69 & $\mathbf{9 c}$ & 19.39 & 49.96 & 50.15 & 80.04 \\
$\mathbf{5 f}$ & 55.87 & 86.92 & $\mathrm{NI}$ & 77.42 & $\mathbf{9 d}$ & $\mathrm{Nd}$ & 200 & $\mathrm{Nd}$ & $\mathrm{Nd}$ \\
$\mathbf{6}$ & 98.39 & 123 & 147 & $\mathrm{NI}$ & $\mathbf{9 e}$ & 151 & 125 & 143 & 74.13 \\
$\mathbf{7 a}$ & 69.36 & 86.29 & 73.56 & 99.13 & $\mathbf{5 - F u}$ & 37.74 & 18.26 & 32.50 & 25.39 \\
\hline
\end{tabular}

${ }^{\mathrm{a}} \mathrm{IC}_{50}(\mu \mathrm{M})$ : the concentration of substance that provides $50 \%$ inhibition.

${ }^{\mathrm{b}}$ No inhibition at $100 \mu \mathrm{M}$. ${ }^{\mathrm{c}}$ No detection. ${ }^{\mathrm{d}}$ Fluorouracil.

IR $\left(\mathrm{KBr}, \mathrm{cm}^{-1}\right): 3347,3103,2935,2800,2758,1749,1605,1588$, $1515,1445,1278,1227,1172,944,840 .{ }^{1} \mathrm{H}$ NMR $(400 \mathrm{MHz}$, $\mathrm{CDCl}_{3}$ and $\left.\mathrm{CD}_{3} \mathrm{COCD}_{3}, \mathrm{ppm}\right) \delta: 7.73(\mathrm{~d}, J=8.72 \mathrm{~Hz}, 2 \mathrm{H}$, $\mathrm{Ph}), 6.96(\mathrm{~d}, J=8.56 \mathrm{~Hz}, 2 \mathrm{H}, \mathrm{Ph}), 6.41(\mathrm{~s}, 1 \mathrm{H},=\mathrm{CH}), 6.10$ $(\mathrm{s}, 1 \mathrm{H},=\mathrm{CH}), 3.46(\mathrm{~s}, 2 \mathrm{H}), 2.46(\mathrm{~s}, 4 \mathrm{H}), 1.65(\mathrm{~m}, 4 \mathrm{H})$, and $1.26(\mathrm{~m}, 2 \mathrm{H}) ;{ }^{13} \mathrm{C}$ NMR $\left(100.6 \mathrm{MHz}, \mathrm{CDCl}_{3}, \mathrm{ppm}\right) \delta: 157.7$ (C2), 146.4, 132.8, 125.5, 116.1, 114.8, 112.0, 55.0, 25.9, and 24.0. HR-MS (ESI), calcd. $\mathrm{C}_{17} \mathrm{H}_{19} \mathrm{NO}_{3}:[\mathrm{M}+\mathrm{H}]^{+} \mathrm{m} / z$ : 286.1443; found: 286.1459.

4-(Piperidin-1-ylmethyl)-5-(propan-2-ylidene)furan-2(5H)one (5d). Yield: $50 \%$, brown oil. IR $\left(\mathrm{KBr}, \mathrm{cm}^{-1}\right): 2938,2856$, $1744,1624,1588,1447,1129,1032,947,909$, and $876 .{ }^{1} \mathrm{H}$ NMR $\left(400 \mathrm{MHz}, \mathrm{CDCl}_{3}, \mathrm{ppm}\right) \delta: 6.07(\mathrm{~s}, 1 \mathrm{H},=\mathrm{CH}), 3.37$ (d, $J=$ $1.13 \mathrm{~Hz}, 2 \mathrm{H}), 2.42(\mathrm{~s}, 4 \mathrm{H}), 2.04,2.03\left(\mathrm{~s}, 6 \mathrm{H},=\left(\mathrm{CH}_{3}\right)_{2}\right), 1.61$ $(\mathrm{m}, 4 \mathrm{H})$, and $1.46(\mathrm{~m}, 2 \mathrm{H}) ;{ }^{13} \mathrm{C} \mathrm{NMR}\left(100.6 \mathrm{MHz}, \mathrm{CDCl}_{3}\right.$, ppm) $\delta: 169.2$ (C1), 155.9 (C3), 145.2 (C4), 124.2 (C11), 118.1 (C2), 57.3, 54.9, 26.0, 24.1, 21.0, and 19.1. HR-MS (ESI), calcd. $\mathrm{C}_{13} \mathrm{H}_{19} \mathrm{NO}_{2}:[\mathrm{M}+\mathrm{H}]^{+} \mathrm{m} / z: 222.1494$; found: 222.1468 .

(Z)-5-(2-Methoxybenzylidene)-4-(piperidin-1-ylmethyl)furan2(5H)-one (5e). Yield: $46 \%$, pink oil. IR $\left(\mathrm{KBr}, \mathrm{cm}^{-1}\right): 2932$, $1740,1638,1596,1491,1461,1239,1023,982$, and $754 .{ }^{1} \mathrm{H}$ NMR (400 MHz, $\mathrm{CDCl}_{3}, \mathrm{ppm}$ ) $\delta: 7.29-6.80$ (overlap, m, 4H, $\mathrm{Ph}), 6.23\left(\mathrm{~s}, 1 \mathrm{H},=\mathrm{C}_{(11)} \mathrm{H}\right), 5.89\left(\mathrm{~s}, 1 \mathrm{H},=\mathrm{C}_{(2)} \mathrm{H}\right), 3.86(\mathrm{~s}, 3 \mathrm{H}$, $\left.\mathrm{OCH}_{3}\right), 3.73(\mathrm{~m}, 2 \mathrm{H}), 2.53(\mathrm{br}, 4 \mathrm{H}), 1.72(\mathrm{~m}, 4 \mathrm{H})$, and 1.51 (m, 2H). ${ }^{13} \mathrm{C}$ NMR $\left(100.6 \mathrm{MHz}, \mathrm{CDCl}_{3}, \mathrm{ppm}\right) \delta: 171.7,166.2$, $157.2,129.2,128.5,127.4,121.8,120.8,111.0,87.6,68.7,56.6$, 55.6, 54.6, 25.4, and 23.6. HR-MS (ESI), calcd. $\mathrm{C}_{18} \mathrm{H}_{21} \mathrm{NO}_{3}$ : $[\mathrm{M}+\mathrm{H}]^{+} \mathrm{m} / z: 300.1600$; found: 300.1598 .

(Z)-5-(Benzo[d][1,3]dioxol-5-ylmethylene)-4-(piperidin-1ylmethyl)furan-2(5H)-one (5f). Yield: 55\%, pink oil. IR ( $\mathrm{KBr}$, $\left.\mathrm{cm}^{-1}\right): 2929,2854,1761,1623,1489,1447,1005$, and $470 .{ }^{1} \mathrm{H}$ NMR (400 MHz, $\left.\mathrm{CDCl}_{3}, \mathrm{ppm}\right) \delta: 7.48$ (s, 1H, Ph), 7.18 (d, $J=7.68 \mathrm{~Hz}, 1 \mathrm{H}, \mathrm{Ph}), 6.83(\mathrm{~d}, J=8.13 \mathrm{~Hz}, 1 \mathrm{H}, \mathrm{Ph}), 6.34$ (s, $\left.1 \mathrm{H},=\mathrm{C}_{(11)} \mathrm{H}\right), 6.08\left(\mathrm{~s}, 1 \mathrm{H},=\mathrm{C}_{(2)} \mathrm{H}\right), 6.01\left(\mathrm{~s}, 2 \mathrm{H}, \mathrm{OCH}_{2} \mathrm{O}\right)$, $3.49(\mathrm{~d}, J=19.46 \mathrm{~Hz}, 2 \mathrm{H}), 2.44(\mathrm{~s}, 4 \mathrm{H}), 1.62(\mathrm{~m}, 4 \mathrm{H})$, and $1.26(\mathrm{~m}, 2 \mathrm{H}) ;{ }^{13} \mathrm{C} \mathrm{NMR}\left(100.6 \mathrm{MHz}, \mathrm{CDCl}_{3}, \mathrm{ppm}\right) \delta: 169.5$ (C1), 157.4 (C3), 148.4 (C4), 148.2 (Ph), 146.6 (Ph), $127.2(\mathrm{Ph})$, $126.1(\mathrm{Ph}), 115.0(\mathrm{Ph}), 111.3(\mathrm{Ph}), 110.1\left(\mathrm{OCH}_{2} \mathrm{O}\right), 108.4(\mathrm{C} 2)$,
101.4 (C11), 54.9, 25.9, 24.0. HR-MS (ESI), calcd. $\mathrm{C}_{18} \mathrm{H}_{19} \mathrm{NO}_{4}$ : $[\mathrm{M}+\mathrm{H}]^{+} m / z: 314.1392$; found: 314.1362 .

3.1.3. 4-((Benzyl(methyl)amino)methyl)furan-2(5H)-one (6). To a $\mathrm{CH}_{3} \mathrm{CN}(50 \mathrm{~mL})$ solvent of compound $3(0.1 \mathrm{~mol}) 1.2$ eq methyl benzylamine $(0.12 \mathrm{~mol})$ and catalytic amount of anhydrous sodium carbonate were added. The mixture was stirred at room temperature for $3 \mathrm{~h}$ and the reaction was monitored by TLC until completion. The reaction solution was evaporated under reduced pressure to steam out most of the $\mathrm{CH}_{3} \mathrm{CN}$ solvent, the reaction mixture was washed with water and ethyl acetate, dried and purified by column chromatography (elution with chloroform ether-ethylacetate, $4: 1)$ which afforded $19.5 \mathrm{~g}$ compound 6. Yellow oil. Yield: 90\%. ${ }^{1} \mathrm{H}$ NMR $\left(400 \mathrm{MHz}, \mathrm{CDCl}_{3}, \mathrm{ppm}\right) \delta: 7.31(\mathrm{~m}, 5 \mathrm{H}$, $\mathrm{Ph}), 6.01\left(\mathrm{~s}, 1 \mathrm{H},=\mathrm{C}_{(2)} \mathrm{H}\right), 4.81\left(\mathrm{~s}, 2 \mathrm{H}, \mathrm{C}_{(4)} \mathrm{H}_{2}\right), 3.54(\mathrm{~s}, 2 \mathrm{H}$, $\left.\mathrm{C}_{(7)} \mathrm{H}_{2}\right), 3.34\left(\mathrm{~s}, 2 \mathrm{H}, \mathrm{C}_{(7)} \mathrm{H}_{2}\right), 2.25\left(\mathrm{~s}, 3 \mathrm{H}, \mathrm{NCH}_{3}\right) ;{ }^{13} \mathrm{C} \mathrm{NMR}$ $\left(100.6 \mathrm{MHz}, \mathrm{CDCl}_{3}, \mathrm{ppm}\right) \delta$ : 173.7 (C1), 168.5 (C3), 138.0 $(\mathrm{Ph}), 128.6(\mathrm{Ph}), 127.4(\mathrm{Ph}), 117.0(\mathrm{C} 2), 72.4(\mathrm{C} 4), 62.2$ (C5), 54.5 (C6), $42.8\left(\mathrm{NCH}_{3}\right)$. HR-MS (ESI), calcd. $\mathrm{C}_{13} \mathrm{H}_{15} \mathrm{NO}_{2}$ : $[\mathrm{M}+\mathrm{H}]^{+} \mathrm{m} / z: 218.1181$; found: 218.1149 .

3.1.4. General Procedure for the Preparation of $(7 \boldsymbol{a}-\boldsymbol{d})$. Compound $5(0.01 \mathrm{~mol})$ and anhydrous sodium carbonate $(0.01 \mathrm{~mol})$ were dissolved in methanol solvent, and then the respective aromatic aldehyde $(0.012 \mathrm{~mol})$ was added. The mixture was stirred at room temperature for $3-12 \mathrm{~h}$ and the reaction was monitored by TLC until completion. The reaction solution was evaporated under reduced pressure to steam out of most of the methanol solvent. The reaction mixture was washed with water and ethyl acetate, dried and purified by column chromatography.

(Z)-4-((Benzyl(methyl)amino)methyl)-5-(furan-2-ylmethylene)furan-2(5H)-one (7a). Yield: 44\%, thick brown oil. IR $\left(\mathrm{KBr}, \mathrm{cm}^{-1}\right): 1755,1645,1607,1470,1145,994,745 .{ }^{1} \mathrm{H}$ NMR $\left(400 \mathrm{MHz}, \mathrm{CDCl}_{3}, \mathrm{ppm}\right) \delta: 7.51(\mathrm{~d}, J=1.96 \mathrm{~Hz}, 1 \mathrm{H}, \mathrm{Ar})$, $7.32-7.26(\mathrm{~m}, 5 \mathrm{H}, \mathrm{Ph}), 7.07$ (d, $J=3.60 \mathrm{~Hz}, 1 \mathrm{H}, \mathrm{Ar}), 6.54(\mathrm{~m}$, $1 \mathrm{H}, \mathrm{Ar}), 6.27\left(\mathrm{~s}, 1 \mathrm{H},=\mathrm{C}_{(8)} \mathrm{H}\right), 5.74\left(\mathrm{~s}, 1 \mathrm{H},=\mathrm{C}_{(2)} \mathrm{H}\right), 3.77(\mathrm{~d}, J=$ $14.08 \mathrm{~Hz}, 1 \mathrm{H}), 3.37$ (d, $J=14.08 \mathrm{~Hz}, 1 \mathrm{H}), 3.66-3.45(\mathrm{~m}, 2 \mathrm{H})$, 
and $2.21\left(\mathrm{~s}, 3 \mathrm{H}, \mathrm{CH}_{3}\right) ;{ }^{13} \mathrm{C} \mathrm{NMR}\left(100.6 \mathrm{MHz}, \mathrm{CDCl}_{3}, \mathrm{ppm}\right)$ $\delta$ : 167.6 (C2), 154.2 (C4), 149.0 (C5), 145.5 (Ph), 135.6, 129.7, 128.7, $128.0(\mathrm{Ph}), 115.8,113.3,110.4,99.8,62.7,51.1$, and 41.8 $\left(\mathrm{NCH}_{3}\right)$. HR-MS (ESI), calcd. $\mathrm{C}_{18} \mathrm{H}_{17} \mathrm{NO}_{3}:[\mathrm{M}+\mathrm{H}]^{+} \mathrm{m} / z$ : 296.1287; found: 296.1277.

(Z)-4-((Benzyl(methyl)amino)methyl)-5-(4-(dimethylamino) benzylidene)furan-2(5H)-one ( $7 \boldsymbol{b}$ ). Yield: $70 \%$, thick brown. oil. IR (KBr, cm $\left.{ }^{-1}\right)$ : 2917, 2848, 2801, 1744, 1604, 1526, 1444, 1367, 1168, 930, and 818. ${ }^{1} \mathrm{H}$ NMR (400 MHz, $\left.\mathrm{CDCl}_{3}, \mathrm{ppm}\right)$ $\delta: 7.69(\mathrm{~d}, J=8.96 \mathrm{~Hz}, 2 \mathrm{H}, \mathrm{Ph}), 7.36-7.26(\mathrm{~m}, 5 \mathrm{H}, \mathrm{Ph}), 6.69$ $(\mathrm{d}, J=8.96 \mathrm{~Hz}, 2 \mathrm{H}, \mathrm{Ph}), 6.22\left(\mathrm{~s}, 1 \mathrm{H},=\mathrm{C}_{(8)} \mathrm{H}\right), 6.05(\mathrm{~s}, 1 \mathrm{H}$, $\left.=\mathrm{C}_{(2)} \mathrm{H}\right), 3.58(\mathrm{~s}, 2 \mathrm{H}), 3.08(\mathrm{~s}, 2 \mathrm{H}), 3.03\left(\mathrm{~s}, 6 \mathrm{H}, \mathrm{N}\left(\mathrm{CH}_{3}\right)_{2}\right)$, and $2.12\left(\mathrm{~s}, 3 \mathrm{H}, \mathrm{NCH}_{3}\right) ;{ }^{13} \mathrm{C} \mathrm{NMR}\left(100.6 \mathrm{MHz}, \mathrm{CDCl}_{3}, \mathrm{ppm}\right)$ $\delta: 170.2(\mathrm{C} 1), 157.2(\mathrm{C} 3), 150.8(\mathrm{C} 4), 145.1,138.4,132.6,129.0$, $128.5,127.4,120.9,113.6,112.7,112.0,111.0,62.4$ (C5), 52.8 (C6), $42.9\left(\mathrm{NCH}_{3}\right)$, and $40.1\left(\mathrm{~N}\left(\mathrm{CH}_{3}\right)_{2}\right)$. HR-MS (ESI), calcd. $\mathrm{C}_{22} \mathrm{H}_{24} \mathrm{~N}_{2} \mathrm{O}_{2}:[\mathrm{M}+\mathrm{H}]^{+} \mathrm{m} / z: 349.1916$; found: 349.1934 .

(Z)-4-((Benzyl(methyl)amino)methyl)-5-(2-methoxybenzylidene)furan-2(5H)-one (7c). Yield: 65\%, light yellow oil. IR $\left(\mathrm{KBr}, \mathrm{cm}^{-1}\right): 2926,1767,1642,1599,1491,1460,1247,1025$, 929, 764. ${ }^{1} \mathrm{H}$ NMR $\left(400 \mathrm{MHz}, \mathrm{CDCl}_{3}, \mathrm{ppm}\right) \delta: 7.41-7.26(\mathrm{~m}$, $9 \mathrm{H}, \mathrm{Ph}), 7.01\left(\mathrm{~s}, 1 \mathrm{H},=\mathrm{C}_{(8)} \mathrm{H}\right), 6.19\left(\mathrm{~s}, 1 \mathrm{H},=\mathrm{C}_{(2)} \mathrm{H}\right), 3.91(\mathrm{~s}$, $\left.3 \mathrm{H}, \mathrm{OCH}_{3}\right), 3.54(\mathrm{~s}, 2 \mathrm{H}), 3.37(\mathrm{~s}, 2 \mathrm{H}), 2.28\left(\mathrm{~s}, 3 \mathrm{H}, \mathrm{NCH}_{3}\right)$; ${ }^{13} \mathrm{C}$ NMR $\left(100.6 \mathrm{MHz}, \mathrm{CDCl}_{3}, \mathrm{ppm}\right) \delta: 169.7$ (C1), 158.1 (C3), 157.6, 147.7, 138.4, 131.9, 130.6, 128.8, 128.7, 128.5, 128.4, 127.4, 121.8, 121.1, 115.6, 110.5 (C2), 105.3 (C8), 62.6 (C5), 55.66 (C6), $53.2\left(\mathrm{OCH}_{3}\right), 42.7\left(\mathrm{NCH}_{3}\right)$. HR-MS (ESI), calcd. $\mathrm{C}_{21} \mathrm{H}_{21} \mathrm{NO}_{3}:[\mathrm{M}+\mathrm{H}]^{+} \mathrm{m} / z: 336.1600$; found: 336.1598 .

(Z)-4-((Benzyl(methyl)amino)methyl)-5-(3,4,5-trimethoxybenzylidene)furan-2(5H)-one ( $7 \mathrm{~d})$. Yield: $58 \%$, light yellow oil. IR $\left(\mathrm{KBr}, \mathrm{cm}^{-1}\right): 2939,2841,1753,1585,1504,1457,1422$, $1331,1235,1126,1001 .{ }^{1} \mathrm{H}$ NMR $\left(400 \mathrm{MHz}, \mathrm{CDCl}_{3}, \mathrm{ppm}\right) \delta$ : 7.37 (m, 4H, Ph), 7.14 (s, 1H, Ph), 7.01 (s, 2H, Ph), $6.18(\mathrm{~s}, 1 \mathrm{H}$, $\left.=\mathrm{C}_{(8)} \mathrm{H}\right), 6.17\left(\mathrm{~s}, 1 \mathrm{H},=\mathrm{C}_{(2)} \mathrm{H}\right), 3.89\left(\mathrm{~s}, 6 \mathrm{H}, \mathrm{OCH}_{3}\right), 3.88(\mathrm{~s}$, $\left.3 \mathrm{H}, \mathrm{OCH}_{3}\right), 3.61(\mathrm{~s}, 2 \mathrm{H}), 3.49(\mathrm{~s}, 2 \mathrm{H}), 2.33\left(\mathrm{~s}, 3 \mathrm{H}, \mathrm{NCH}_{3}\right)$; ${ }^{13} \mathrm{C}$ NMR $\left(100.6 \mathrm{MHz}, \mathrm{CDCl}_{3}, \mathrm{ppm}\right) \delta: 169.7$ (C1), 158.2, $157.6,147.7,138.5,131.9,131.6,130.6,130.5$, 128.8. 128.4, 127.4, 121.8, 121.2, 115.6, 115.0, 110.4, 105.3, 103.8, 62.6, 55.6, 53.2, 42.7, and 29.7. HR-MS (ESI), calcd. $\mathrm{C}_{23} \mathrm{H}_{25} \mathrm{NO}_{5}:[\mathrm{M}+\mathrm{H}]^{+} \mathrm{m} / \mathrm{z}$ : 396.1811; found: 396.1807.

3.1.5. 4-((4-Benzoylpiperazin-1-yl)methyl)furan-2(5H)-one (8). To a $\mathrm{CH}_{3} \mathrm{CN}(50 \mathrm{~mL})$ solvent of compound $3(0.1 \mathrm{~mol})$ 1.1 eq. benzoyl piperazine ${ }^{12}(0.11 \mathrm{~mol})$ and catalytic amount of anhydrous sodium carbonate were added. The mixture was stirred at room temperature for $2 \mathrm{~h}$, and the reaction was monitored by TLC until completion. The reaction solution was evaporated under reduced pressure to steam out of most of the $\mathrm{CH}_{3} \mathrm{CN}$ solvent, the reaction mixture was washed with water and ethyl acetate, dried and purified by ethyl acetate crystallize to afforded $27.2 \mathrm{~g}$ compound $\mathbf{8}$. White crystal. Yield: $95 \%, \mathrm{mp}: 112.5-113.0^{\circ} \mathrm{C}$. IR $\left(\mathrm{KBr}, \mathrm{cm}^{-1}\right): 2820,1787$, $1742,1624,1434,1275,1143,1025,894,868,709 .{ }^{1} \mathrm{H}$ NMR $\left(400 \mathrm{MHz}, \mathrm{CDCl}_{3}, \mathrm{ppm}\right) \delta: 7.43(\mathrm{~m}, 5 \mathrm{H}, \mathrm{Ph}), 6.02(\mathrm{~d}, J=$ $\left.1.42 \mathrm{~Hz}, 1 \mathrm{H},=\mathrm{C}_{(2)} \mathrm{H}\right), 4.82(\mathrm{~d}, J=1.54 \mathrm{~Hz}, 2 \mathrm{H}), 3.80-3.46(\mathrm{br}$,
$4 \mathrm{H}), 3.40$ (s, 2H), 2.56-2.42 (br, $4 \mathrm{H}) ;{ }^{13} \mathrm{C}$ NMR $(100.6 \mathrm{MHz}$, $\left.\mathrm{CDCl}_{3}, \mathrm{ppm}\right) \delta: 173.4(\mathrm{C} 1), 170.4,166.6$ (C3), 135.4, 129.9, 128.7, 127.0 (Ph), 117.9 (C2), 72.4 (C4), 55.7 (C5), 53.7, 53.7, 47.5, 41.9. HR-MS (ESI), calcd. $\mathrm{C}_{16} \mathrm{H}_{18} \mathrm{~N}_{2} \mathrm{O}_{3}:[\mathrm{M}+\mathrm{H}]^{+} \mathrm{m} / z$ : 287.1396; found: 287.1392 .

3.1.6. General Procedure for the Preparation of $(\mathbf{9 a}-\mathbf{f})$. Compound $8(0.01 \mathrm{~mol})$ and anhydrous sodium carbonate $(0.01 \mathrm{~mol})$ was dissolved in methanol solvent, then the respective aromatic aldehyde $(0.012 \mathrm{~mol})$ was added. The mixture was stirred at room temperature for $3-12 \mathrm{~h}$ and the reaction was monitored by TLC to complete. The reaction solution was vaporated under reduced pressure to steam out of most of the methanol solvent, the reaction mixture was washed with water and ethyl acetate, dried and purified by column chromatography.

(Z)-4-((4-Benzoylpiperazin-1-yl)methyl)-5-(furan-2-ylmethylene)furan-2(5H)-one (9a). Yield: $82 \%$, brown-red oil. IR $\left(\mathrm{KBr}, \mathrm{cm}^{-1}\right): 1757,1629,1466,1435,1282,997$, and $742 .{ }^{1} \mathrm{H}$ NMR $\left(400 \mathrm{MHz}, \mathrm{CDCl}_{3}, \mathrm{ppm}\right) \delta: 7.51-7.07$ (m, overlap, $6 \mathrm{H}, \mathrm{Ar}), 6.34(\mathrm{~m}, 2 \mathrm{H}, \mathrm{Ar}), 6.31\left(\mathrm{~s}, 1 \mathrm{H},=\mathrm{C}_{(11)} \mathrm{H}\right), 5.73(\mathrm{~s}$, $\left.1 \mathrm{H},=\mathrm{C}_{(2)} \mathrm{H}\right), 3.88-3.51(\mathrm{br}, 4 \mathrm{H}), 3.50(\mathrm{~d}, J=14.28 \mathrm{~Hz}, 2 \mathrm{H})$, 2.75-2.56 (br, $4 \mathrm{H}) ;{ }^{13} \mathrm{CNMR}\left(100.6 \mathrm{MHz}, \mathrm{CDCl}_{3}, \mathrm{ppm}\right)$ $\delta$ : 170.4 (C1), 167.4, 153.9 (C3), 148.8 (C4), 147.2, 135.1, 130.0, 128.6, 127.0, 116.0, 113.3, 110.6, 107.4 (C11), 100.0 (C2), 62.9 (C5), 51.7, 47.6, and 42.1. HR-MS (ESI), calcd. $\mathrm{C}_{21} \mathrm{H}_{20} \mathrm{~N}_{2} \mathrm{O}_{4}$ : $[\mathrm{M}+\mathrm{H}]^{+} \mathrm{m} / \mathrm{z}: 365.1501$; found: 365.1497 .

(Z)-4-((4-Benzoylpiperazin-1-yl)methyl)-5-(4-hydroxy-3methoxybenzylidene)furan-2(5H)-one (9b). Yield: $88 \%$, brown solid mp: $79.0-80.6^{\circ} \mathrm{C}$. IR $\left(\mathrm{KBr}, \mathrm{cm}^{-1}\right): 2921,2852$, $1752,1630,1580,1515,1431,1284,1163,1131$, and $1026 .{ }^{1} \mathrm{H}$ NMR $\left(400 \mathrm{MHz}, \mathrm{CDCl}_{3}, \mathrm{ppm}\right) \delta: 7.40(\mathrm{~s}, 1 \mathrm{H}, \mathrm{Ph}), 7.36(\mathrm{~m}$, $5 \mathrm{H}, \mathrm{Ph}), 7.15(\mathrm{~m}, 1 \mathrm{H}), 6.86(\mathrm{~d}, J=8.24 \mathrm{~Hz}, 1 \mathrm{H}, \mathrm{Ph}), 6.23$ $\left(\mathrm{s}, 1 \mathrm{H},=\mathrm{C}_{(11)} \mathrm{H}\right), 6.05\left(\mathrm{~s}, 1 \mathrm{H},=\mathrm{C}_{(2)} \mathrm{H}\right), 3.85\left(\mathrm{~s}, 3 \mathrm{H}, \mathrm{OCH}_{3}\right)$, 3.80, 3.44 (br, $4 \mathrm{H}), 3.48$ (s, $2 \mathrm{H}), 2.58,2.42(\mathrm{br}, 4 \mathrm{H}) ;{ }^{13} \mathrm{C}$ NMR (100.6 MHz, $\left.\mathrm{CDCl}_{3}, \mathrm{ppm}\right) \delta: 170.5(\mathrm{Cl}), 169.5(\mathrm{C} 10)$, 156.1 (C3), 147.5, 147.1, 145.9, 135.3, 129.9, 128.5, 127.0, 125.6, 125.1, 115.0, 112.7 (C2), 112.1 (C11), 56.0 (C5), $53.7\left(\mathrm{OCH}_{3}\right)$, 53.5, 53.1, 47.6, and 42.1. HR-MS (ESI), calcd. $\mathrm{C}_{24} \mathrm{H}_{24} \mathrm{~N}_{2} \mathrm{O}_{5}$ : $[\mathrm{M}+\mathrm{H}]^{+} \mathrm{m} / z: 421.1763$; found: 421.1735 .

(Z)-4-((4-Benzoylpiperazin-1-yl)methyl)-5-(4-hydroxybenzylidene)furan-2(5H)-one (9c). Yield: $89 \%$, yellow crystals, mp: $239.1-240.0^{\circ} \mathrm{C}$. IR $\left(\mathrm{KBr}, \mathrm{cm}^{-1}\right): 3447,1762,1604,1513$, 1446, 1279, 1021, and 998. ${ }^{1} \mathrm{H}$ NMR $\left(400 \mathrm{MHz}, \mathrm{CDCl}_{3}\right.$ and $\left.\mathrm{CD}_{3} \mathrm{COCD}_{3}, \mathrm{ppm}\right) \delta: 7.72(\mathrm{~d}, J=8.72 \mathrm{~Hz}, 2 \mathrm{H}, \mathrm{Ph}), 6.92(\mathrm{~d}, J$ $=6.92 \mathrm{~Hz}, 2 \mathrm{H}, \mathrm{Ph}), 7.42(\mathrm{~m}, 5 \mathrm{H}, \mathrm{Ph}), 6.40\left(\mathrm{~s}, 1 \mathrm{H},=\mathrm{C}_{(11)} \mathrm{H}\right)$, $6.11\left(\mathrm{~s}, 1 \mathrm{H},=\mathrm{C}_{(3)} \mathrm{H}\right), 3.85-3.46(\mathrm{br}, 4 \mathrm{H}), 3.85(\mathrm{~s}, 2 \mathrm{H})$, and 2.66-2.49 (br, 4H); ${ }^{13} \mathrm{C}$ NMR $\left(100.6 \mathrm{MHz}, \mathrm{CDCl}_{3}, \mathrm{ppm}\right)$ $\delta: 170.4,169.4,156.1,145.9,129.9,128.6,127.1,124.8,116.1$, 115.0, 56.0, 53.5, 47.6. HR-MS (ESI), calcd. $\mathrm{C}_{23} \mathrm{H}_{22} \mathrm{~N}_{2} \mathrm{O}_{4}$ : $[\mathrm{M}+\mathrm{H}]^{+} \mathrm{m} / z: 391.1658$; found: 391.1627 .

(Z)-4-((4-Benzoylpiperazin-1-yl)methyl)-5-benzylidenefuran2(5H)-one (9d). Yield: 78\%, light yellow solid, mp: $65.2-$ $66.4^{\circ} \mathrm{C}$. IR $\left(\mathrm{KBr}, \mathrm{cm}^{-1}\right): 1758,1627,1434,1280,994,697$. 
${ }^{1} \mathrm{H}$ NMR $\left(400 \mathrm{MHz}^{\mathrm{CDCl}}{ }_{3}, \mathrm{ppm}\right) \delta: 7.80(\mathrm{~d}, J=7.38 \mathrm{~Hz}, 2 \mathrm{H}$, $\mathrm{Ph}), 7.44-7.21(\mathrm{~m}, 8 \mathrm{H}, \mathrm{Ph}), 6.21\left(\mathrm{~s}, 1 \mathrm{H},=\mathrm{C}_{(11)} \mathrm{H}\right), 5.86(\mathrm{~s}, 1 \mathrm{H}$, $\left.=\mathrm{C}_{(2)} \mathrm{H}\right), 3.76-3.43(\mathrm{br}, 4 \mathrm{H}), 3.39(\mathrm{~d}, J=10.70 \mathrm{~Hz}, 2 \mathrm{H})$, and 2.72-2.53 (br, 4H); $\left.{ }^{13} \mathrm{C} \mathrm{NMR} \mathrm{(100.6} \mathrm{MHz,} \mathrm{CDCl}_{3}, \mathrm{ppm}\right) \delta$ : 170.4 (C1), 168.6, 147.6, 147.4, 141.9, 135.0, 132.5, 132.5, 130.8, 130.1, 129.6, 128.9, 128.6, 128.6, 128.4, 128.4, 127.7, 127.0, 125.8, 125.4, 111.1 (C11), 67.6 (C5), 53.2, 52.9, 47.0, 41.5. HR-MS (ESI), calcd. $\mathrm{C}_{23} \mathrm{H}_{22} \mathrm{~N}_{2} \mathrm{O}_{3}$ : $[\mathrm{M}+\mathrm{H}]^{+} \mathrm{m} / z$ : 375.1709; found: 375.1716 .

(Z)-4-((4-Benzoylpiperazin-1-yl)methyl)-5-(2-methoxybenzylidene)furan-2(5H)-one (9e). Yield: $85 \%$, light yellow solid, mp: $199.3-200.5^{\circ} \mathrm{C} .{ }^{1} \mathrm{H}$ NMR $\left(400 \mathrm{MHz}, \mathrm{CDCl}_{3}, \mathrm{ppm}\right) \delta$ : $7.42-6.83(\mathrm{~m}, 9 \mathrm{H}, \mathrm{Ph}), 6.68\left(\mathrm{~s}, 1 \mathrm{H},=\mathrm{C}_{(11)} \mathrm{H}\right), 5.93(\mathrm{~s}, 1 \mathrm{H}$, $\left.=\mathrm{C}_{(2)} \mathrm{H}\right), 3.90,3.55\left(\mathrm{br}, 4 \mathrm{H}, \mathrm{C}_{(7,8,)} \mathrm{H}_{2}\right), 3.74\left(\mathrm{~s}, 3 \mathrm{H}, \mathrm{OCH}_{3}\right)$, $3.29\left(\mathrm{~m}, 2 \mathrm{H}, \mathrm{C}_{(5)} \mathrm{H}_{2}\right)$, and $2.92-2.53\left(\mathrm{br}, 4 \mathrm{H}, \mathrm{C}_{(6,9)} \mathrm{H}_{2}\right) .{ }^{13} \mathrm{C}$ NMR $\left(100.6 \mathrm{MHz}, \mathrm{CDCl}_{3}, \mathrm{ppm}\right) \delta: 170.4,168.3,157.4,156.2$, $147.4,132.6,131.6,130.7,128.9,128.6,128.5,127.1,127.0,125.7$, $121.1,120.0,110.6,103.8,63.6,55.6,55.3$, and 50.7. HR-MS (ESI), calcd. $\mathrm{C}_{24} \mathrm{H}_{24} \mathrm{~N}_{2} \mathrm{O}_{4}:[\mathrm{M}+\mathrm{H}]^{+} \mathrm{m} / z$ : 405.1814; found: 405.1846 .

\section{Conclusions}

In summary, a series of novel $\gamma$-alkylidene butenolides bearing nitrogen unit have been synthesized by a simple and general method in good yields. Their antibacterial activity and cytotoxic activity were evaluated. The results revealed that the introduction of nitrogen heterocyclic and $\gamma$-alkylidene to the lactone was efficient for the bioactivities.

\section{Conflict of Interests}

There is no conflict of interests to declare.

\section{Acknowledgment}

This work was financially supported by the Doctoral Research Foundation of Henan University of TCM (no. BSJJ2010-03).

\section{Endnotes}

1. In vitro antibacterial activity was studied with tube double dilution method. In order to study the bacteriostasis to staphylococcus aureus and Escherichia coli. The minimum inhibitory concentration (MIC) was measured. The sample was dissolved to $1.0 \mathrm{mg} / \mathrm{mL}$ high concentration solution, geometric diluted to less than $200 \mu \mathrm{g} / \mathrm{mL}$ for several different concentration. The bacterias have been incubated $16-18 \mathrm{~h}$ and diluted 200 times, in the above-mentioned several different concentrations of liquid by adding $0.1 \mathrm{~mL}$ solution of bacteria. With a sample solution without bacteria as a test group, to observe whether the liquid was contaminated, a solution of diluted bacteria without sample was used as a control group to observe whether the bacteria can grow and another tube with only $1 \mathrm{~mL}$ medium was used as a blank control group to observe whether the medium was contaminated. Samples for each of the groups were activated in a shaker with $225 \mathrm{r} / \mathrm{min}$ and $37^{\circ} \mathrm{C}$ for $16-$ $18 \mathrm{~h}$ to check the results. With naked eye to observe the clear level of each group's medium and sequential observation of drug control tubes, control tubes, and control tubes of bacteria, control tubes needed to be clarified; otherwise it would mean that samples or medium has been contaminated. The control tube of bacteria that has become muddy proved to have normal bacterial growth. Comparison of the test tube, among the test tubes with clarified liquid medium, with the minimum sample concentration poses the drug concentration as the minimum inhibitory concentration of drugs. All the experiment was carried out in triplicate.

2. In vitro cytotoxicity study: the cells were purchased from the Type Culture Collection of the Chinese Academy of Sciences, Shanghai, China. The cytotoxicity of compounds at various concentrations or fluorouracil $(10 \mu \mathrm{g} / \mathrm{mL})$ was measured by MTT(3$[4,5]$-dimethylthiazol-2-yl-2,5-di-phenyltetra-zolium bromide) method. HepG-2.2.15 cells $\left(3.0 \times 10^{4}\right.$ cells $\left./ \mathrm{mL}\right)$ were seeded in 96-wellplates for $24 \mathrm{~h}$. After attachment to plates, the supernatants in each well were replaced very carefully with $200 \mu \mathrm{L}$ of fresh RMPI1640 containing different concentrations of the compounds or fluorouracil. Untreated cells were used as the control. Remove the medium after HepG-2.2.15 cells were treated for 3 days as explained previously. Cells were cultured at $37^{\circ} \mathrm{C}$ for $4 \mathrm{~h}$ after $150 \mu \mathrm{L}$ of DMEM medium containing MTT $(5 \mathrm{mg} / \mathrm{mL})$ was added into each well. Remove the medium and add $200 \mu \mathrm{L}$ of DMSO into each well. The absorption $(A)$ at $490 \mathrm{~nm}$ was measured after a ten-minute shaking. The $\mathrm{IC}_{50}$ value was the concentration that achieved 50\% cytotoxicity to HepG2.2.15. All the experiment was carried out in triplicate. Data were analyzed statistically by the SPSS11.5 program software package, and a $P$ value of 0.05 was regarded as significant.

\section{References}

[1] I. L. Doerr and R. E. Willette, "Synthesis of 5-(9-adenyl)-4ethyl-3-methyl-5(H)-furanone," Tetrahedron Letters, vol. 11, no. 9, pp. 667-668, 1970.

[2] J. A. Pettus Jr., R. M. Wing, and J. J. Sims, "Marine Natural Products XII Isolation of a Family of Multihalogenated GammaMethylene Lactones from the Red Seaweed Delisea fimbriata," Tetrahedron Letters, vol. 18, no. 1, pp. 41-44, 1977.

[3] S. M. Kupchan, M. A. Eakin, and A. M. Thomas, "Tumor inhibitors. 69. Structure-cytotoxicity relationships among the sesquiterpene lactones," Journal of Medicinal Chemistry, vol. 14, no. 12, pp. 1147-1152, 1971.

[4] S. M. Kupchan, D. C. Fessler, M. A. Eakin, and T. J. Giacobbe, "Reactions of alpha methylene lactone tumor inhibitors with model biological nucleophiles," Science, vol. 168, no. 3929, pp. 376-378, 1970 .

[5] G. A. Kraus and H. J. Sugimoto, "General route to $\gamma$-alkylidene butenolides," Journal of the Chemical Society, Chemical Communications, vol. 30, no. 1, 1978. 
[6] X. Lu, X. Huang, and S. Ma, "A convenient synthesis of $\gamma$-(Z)alkylidene butenolides," Tetrahedron Letters, vol. 34, no. 37, pp. 5963-5966, 1993.

[7] J. Bigorra, J. Font, C. Ochoa de Echaguen, and R. M. Ortuno, "Synthetic approaches to either homochiral or achiral derivatives of 3-hydroxy-2(5H)-furanone (isotetronic acid)," Tetrahedron, vol. 49, no. 30, pp. 6717-6728, 1993.

[8] I. L. Doerr and R. E. Willette, " $\alpha, \beta$-Unsaturated lactones. I. Condensation of 5-bromo-2 $(5 \mathrm{H})$-furanones with adenine and uracil derivatives," Journal of Organic Chemistry, vol. 38, no. 22, pp. 3878-3887, 1973.

[9] R. Kazlauskas, P. T. Murphy, R. J. Quinn, and R. J. Wells, “A new class of halogenated lactones from the red alga delisea fimbriata (bonnemaisoniaceae)," Tetrahedron Letters, vol. 18, no. 1, pp. 3740, 1977.

[10] F. Bellina, C. Anselmi, and R. Rossi, "Total synthesis of rubrolide $\mathrm{M}$ and some of its unnatural congeners," Tetrahedron Letters, vol. 43, no. 11, pp. 2023-2027, 2002.

[11] R. R. Teixeira, L. C. A. Barbosa, J. O. Santana et al., "Synthesis and structural characterization of two nostoclide analogues," Journal of Molecular Structure, vol. 837, no. 1-3, pp. 197-205, 2007.

[12] X. M. Yang and S. Yuzuru, "Nostoclide I and II, extracellular metabolites from a symbiotic cyanobacterium, Nostoc sp., from the lichen Peltigera canina," Tetrahedron Letters, vol. 34, no. 5, pp. 761-764, 1993.

[13] B. John, M. FranCois, and L. Nicolas, "Furanolate-based strategy for sequential 2,3,4-trisubstitution of butenolide: total synthesis of nostoclides I and II," Tetrahedron Letters, vol. 35, no. 43, pp. 7897-7900, 1994.

[14] D. Kuhnt, T. Anke, H. Besl et al., "Antibiotics from basidiomycetes. XXXVII. New inhibitors of cholesterol biosynthesis from cultures of Xerula melanotricha dorfelt," Journal of Antibiotics, vol. 43, no. 11, pp. 1413-1420, 1990.

[15] H. Fáková, M. Pour, J. Kuneš, and P. Šenel, "Carbonylative lactonization via carbonyl oxygen attack: a short and selective total synthesis of uncinine and its analogues," Tetrahedron Letters, vol. 46, no. 47, pp. 8137-8140, 2005.

[16] T.-J. Hsieh, F.-R. Chang, Y.-C. Chia et al., "The alkaloids of artabotrys uncinatus," Journal of Natural Products, vol. 64, no. 9, pp. 1157-1161, 2001.

[17] D. Kuhnt, T. Anke, H. Besl et al., "Antibiotics from basidiomycetes. XXXVII. New inhibitors of cholesterol biosynthesis from cultures of Xerula melanotricha dorfelt," Journal of Antibiotics, vol. 43, no. 11, pp. 1413-1420, 1990.

[18] M. J. Ortega, E. Zubia, J. M. Ocana, S. Naranjo, and J. Salv á, "New rubrolides from the ascidian Synoicum blochmanni," Tetrahedron, vol. 56, no. 24, pp. 3963-3967, 2000.

[19] Y. S. Rao, "Chemistry of butenolides," Chemical Reviews, vol. 64, no. 4, pp. 353-388, 1964.

[20] Y. S. Rao, "Recent advances in the chemistry of unsaturated lactones," Chemical Reviews, vol. 76, no. 5, pp. 625-694, 1976.

[21] S. Ma, Z. Shi, and Z. Yu, "Synthesis of $\beta$-halobutenolides and their $\operatorname{Pd}(0)$-catalyzed cross-coupling reactions with terminal alkynes and organozinc reagents. A general route to $\beta$-substituted butenolides and formal synthesis of cis-whisky lactone," Tetrahedron, vol. 55, no. 41, pp. 12137-12148, 1999.

[22] T. K. M. Shing, V. W. F. Tai, and H. C. J. Tsui, "Gonibutenolides $\mathrm{A}$ and B: serendipitous syntheses, relative and absolute configuration," Journal of the Chemical Society, Chemical Communications, vol. 11, no. 11, pp. 1293-1294, 1994.
[23] T. K. M. Shing, H.-C. Tsui, and Z.-H. Zhou, "Enantiospecific syntheses of (+)-goniofufurone, (+)-7-epi-goniofufurone, $(+)$ goniobutenolide A, (-)-goniobutenolide $\mathrm{B},(+)$-goniopypyrone, (+)-altholactone, (+)-goniotriol, and (+)-7-acetylgoniotriol," Journal of Organic Chemistry, vol. 60, no. 10, pp. 3121-3130, 1995.

[24] N. Didry, L. Dubreuil, and M. Pinkas, "Microbiological properties of protoanemonin isolated from Ranunculus bulbosus," Phytotherapy Research, vol. 7, no. 1, pp. 21-24, 1993.

[25] M. L. Martin, L. S. Roman, and A. Dominguez, "In vitro activity of protoanemonin, an antifungal agent," Planta Medica, vol. 56, no. 1, pp. 66-69, 1990.

[26] D. Alonso, J. Font, and R. M. Ortuno, "Diels-Alder reactions of protoanemonin with heterosubstituted dienes. Synthesis of polyfunctional oxaspiro[4.5]decanes," Tetrahedron, vol. 47, no. 30, pp. 5895-5900, 1991.

[27] S. Antane, C. E. Caufield, W. Hu et al., "Pulvinones as bacterial cell wall biosynthesis inhibitors," Bioorganic and Medicinal Chemistry Letters, vol. 16, no. 1, pp. 176-180, 2006.

[28] C. E. Caufiled, S. A. Antane, K. M. Morris et al., "3-aryl-4hydroxyfuranone compounds and pharmaceutical and veterinary compositions containing them," WO2005019196, 2005.

[29] J. Zhou, A. Bhattacharjee, S. Chen et al., "Design at the atomic level: generation of novel hybrid biaryloxazolidinones as promising new antibiotics," Bioorganic and Medicinal Chemistry Letters, vol. 18, no. 23, pp. 6179-6183, 2008.

[30] A. E. Amr, M. I. Hegab, A. A. Ibrahim, and M. M. Abdalah, "Synthesis and reactions of some fused oxazinone, pyrimidinone, thiopyrimidinone, and triazinone derivatives with a thiophene ring as analgesic, anticonvulsant, and antiparkinsonian agents," Monatschefte Fur Chemie, vol. 134, no. 10, pp. 1395-1409, 2003.

[31] A. E. Amr and G. M. H. Abou, "Synthesis and investigation of a new cyclo ( $N^{\alpha}$-dipicolinoyl) pentapeptide of a breast and CNS cytotoxic activity and an ionophoric specificity," Amino Acids, vol. 26, no. 3, pp. 283-289, 2004.

[32] M. F. Brana, J. M. Castellano, M. Mpran et al., "Bisnaphthalimides. 2. Synthesis and biological activity of 5,6acenaphthalimidoalkyl-1,8-naphthalimidoalkyl amines," European Journal of Medicinal Chemistry, vol. 30, no. 3, pp. 235-239, 1995.

[33] N. Kojima, T. Fushimi, N. Maezaki, T. Tanaka, and T. Yamori, "Synthesis of hybrid acetogenins, $\alpha, \beta$-unsaturated- $\gamma$-lactonefree nitrogen-containing heterocyclic analogues, and their cytotoxicity against human cancer cell lines," Bioorganic and Medicinal Chemistry Letters, vol. 18, no. 5, pp. 1637-1641, 2008.

[34] A. R. Renslo, G. W. Luehr, S. Lam et al., "Synthesis and structureactivity studies of antibacterial oxazolidinones containing dihydrothiopyran or dihydrothiazine C-rings," Bioorganic \& Medicinal Chemistry Letters, vol. 16, no. 13, pp. 3475-3478, 2006.

[35] E. Aiello, S. Aiello, F. Mingoia et al., "Synthesis and antimicrobial activity of new 3-(1-R-3(5)-methyl-4-nitroso-1H5(3)-pyrazolyl)-5-methylisoxazoles," Bioorganic and Medicinal Chemistry, vol. 8, no. 12, pp. 2719-2728, 2000.

[36] G. H. Hakimelahi, K.-S. Shia, C. Xue et al., "Design, synthesis, and biological evaluation of a series of $\beta$-lactam-based prodrugs," Bioorganic and Medicinal Chemistry, vol. 10, no. 11, pp. 3489-3498, 2002.

[37] M. F. Gordeev, C. Hackbarth, M. R. Barbachyn et al., "Novel oxazolidinone-quinolone hybrid antimicrobials," Bioorganic and Medicinal Chemistry Letters, vol. 13, no. 23, pp. 4213-4216, 2003. 
[38] H. W. Xu, J. F. Wang, G. Z. Liu, G. F. Hong, and H. M. Liu, "Facile synthesis of $\gamma$-alkylidenebutenolides," Organic \& Biomolecular Chemistry, vol. 5, pp. 1247-1250, 2007.

[39] H. W. Xu, G. F. Dai, G. Z. Liu, J. F. Wang, and H. M. Liu, "Synthesis of andrographolide derivatives: a new family of $\alpha$ glucosidase inhibitors," Bioorganic \& Medicinal Chemistry, vol. 15, no. 12, pp. 4247-4255, 2007.

[40] H. W. Xu, G. Z. Liu, G. F. Dai, C. L. Wu, and H. M. Liu, "Modification of 15-akylidene andrographolide derivatives as alpha-glucosidase inhibitor," Drug Discoveries \& Therapeutics, vol. 1, no. 1, pp. 73-77, 2007.

[41] G. F. Dai, H. W. Xu, J. F. Wang, F. W. Liu, and H. M. Liu, "Studies on the novel $\alpha$-glucosidase inhibitory activity and structure-activity relationships for andrographolide analogues," Bioorganic \& Medicinal Chemistry Letters, vol. 16, no. 10, pp. 2710-2713, 2006.

[42] E. S. Wang, Y. M. Choy, and H. N. C. Wong, "Synthetic studies on prehispanolone and 14,15-dihydroprehispanolone," Tetrahedron, vol. 52, no. 37, pp. 12137-12158, 1996.

[43] R. K. Boeckman Jr and S. S. Ko, "Stereochemical control in the intramolecular Diels-Alder reaction. 2. Structural and electronic effects on reactivity and selectivity," Journal of the American Chemical Society, vol. 104, no. 4, pp. 1033-1041, 1982.

[44] G. Z. Liu, H. W. Xu, G. W. Chen et al., "Stereoselective synthesis of desloratadine derivatives as antagonist of histamine," Bioorganic \& Medicinal Chemistry, vol. 18, no. 4, pp. 1626-1632, 2010. 

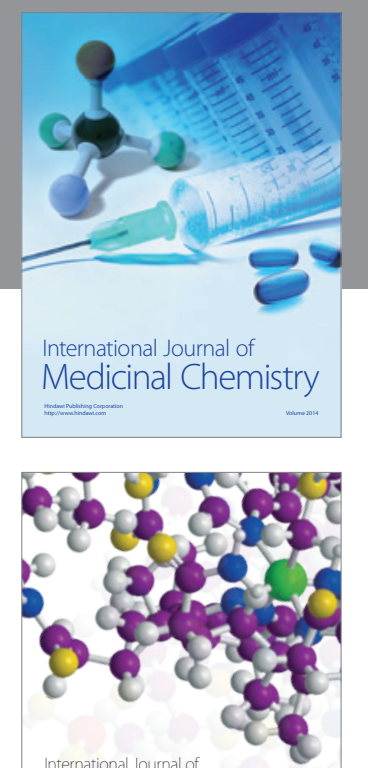

\section{Carbohydrate} Chemistry

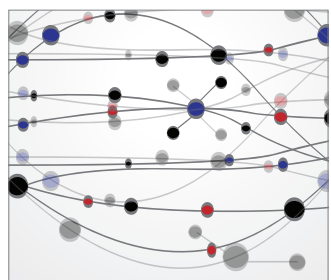

The Scientific World Journal
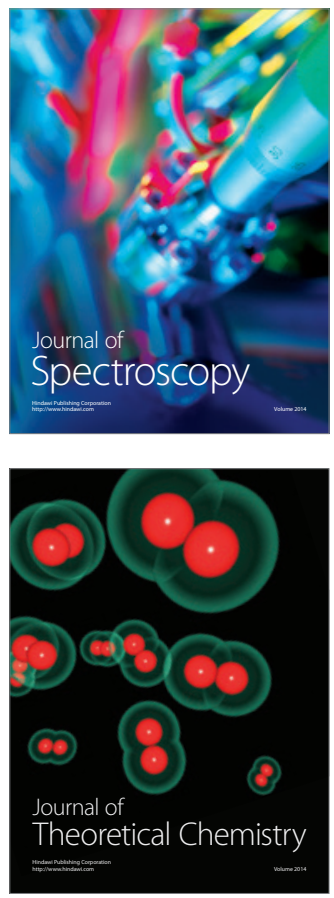
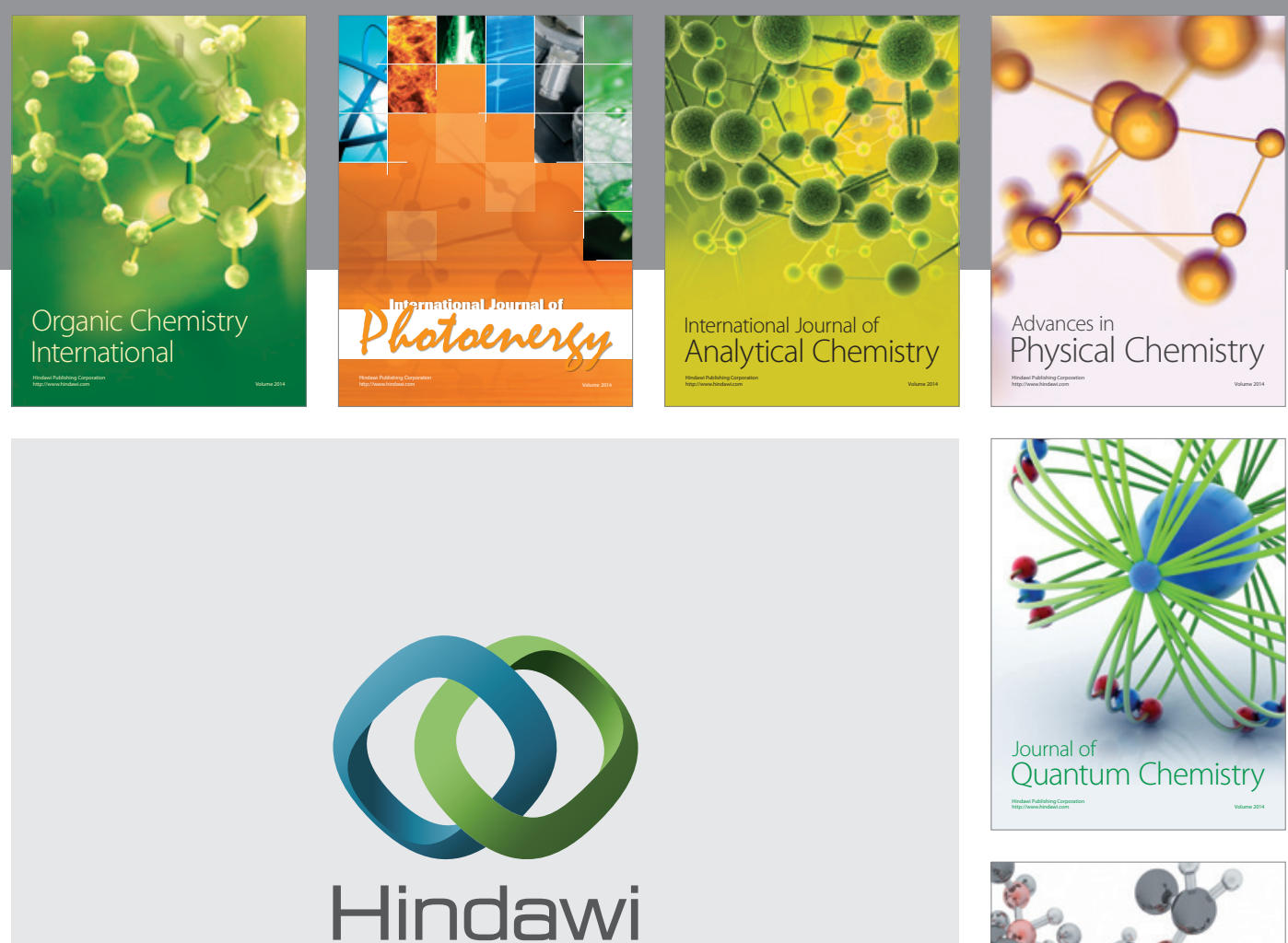

Submit your manuscripts at

http://www.hindawi.com

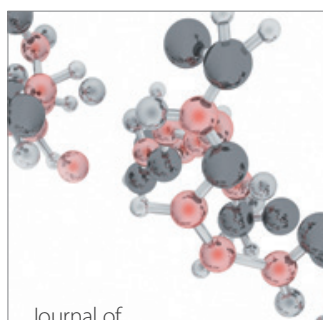

Analytical Methods

in Chemistry

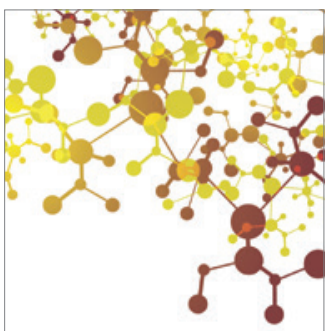

Journal of

Applied Chemistry

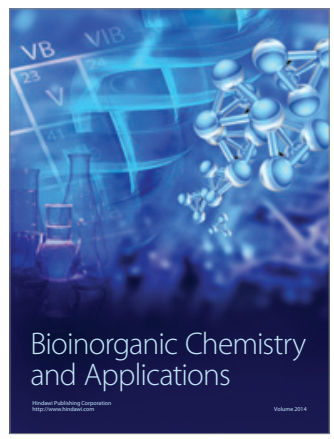

Inorganic Chemistry
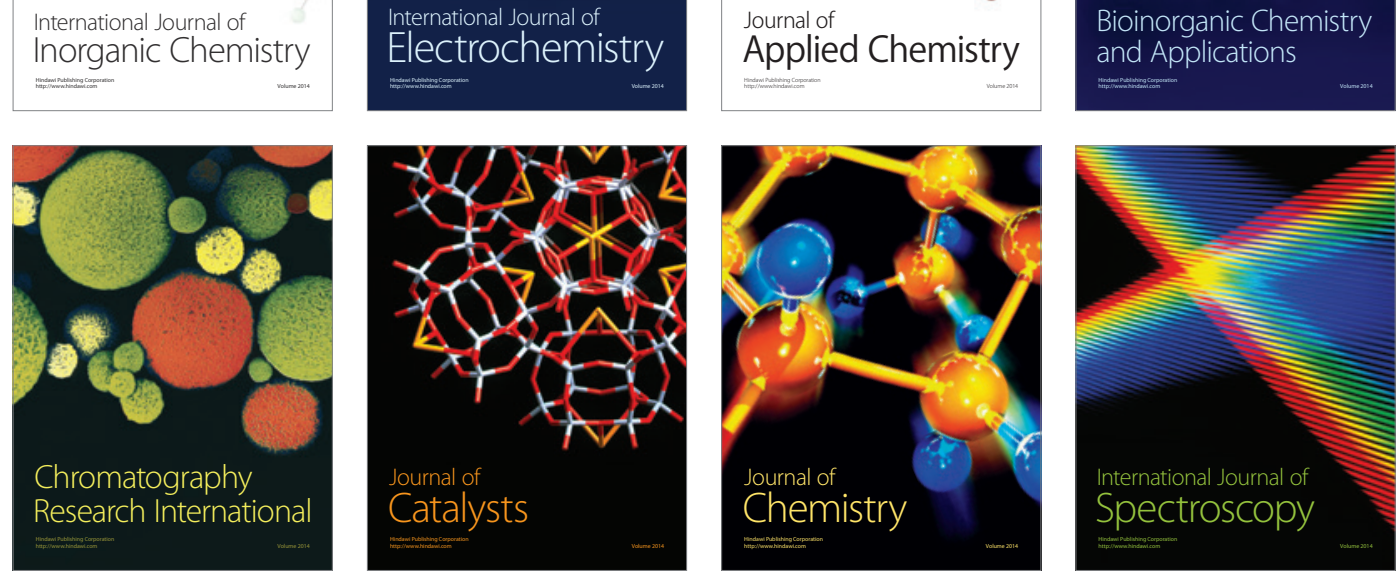